\title{
Insight
}

\section{Adaptive Capacity and Traps}

\author{
$\underline{\text { Stephen R. Carpenter }}^{1}$ and William A. Brock ${ }^{1}$
}

\begin{abstract}
Adaptive capacity is the ability of a living system, such as a social-ecological system, to adjust responses to changing internal demands and external drivers. Although adaptive capacity is a frequent topic of study in the resilience literature, there are few formal models. This paper introduces such a model and uses it to explore adaptive capacity by contrast with the opposite condition, or traps. In a socialecological rigidity trap, strong self-reinforcing controls prevent the flexibility needed for adaptation. In the model, too much control erodes adaptive capacity and thereby increases the risk of catastrophic breakdown. In a social-ecological poverty trap, loose connections prevent the mobilization of ideas and resources to solve problems. In the model, too little control impedes the focus needed for adaptation. Fluctuations of internal demand or external shocks generate pulses of adaptive capacity, which may gain traction and pull the system out of the poverty trap. The model suggests some general properties of traps in social-ecological systems. It is general and flexible, so it can be used as a building block in more specific and detailed models of adaptive capacity for a particular region.
\end{abstract}

Key Words: adaptation; allostasis; model; poverty trap; resilience; rigidity trap; transformation

\section{INTRODUCTION}

How do transformation and persistence coexist in living systems? This paradox is addressed by the concept of resilience (Holling 1973, Folke 2006). Resilience is not about an equilibrium of transformation and persistence. Instead, it explains how transformation and persistence work together, allowing living systems to assimilate disturbance, innovation, and change, while at the same time maintaining characteristic structures and processes (Westley et al. 2006).

Resilience is a broad, multifaceted, and loosely organized cluster of concepts, each one related to some aspect of the interplay of transformation and persistence. Thus, resilience does not come down to a single testable theory or hypothesis. Instead it is a changing constellation of ideas, some of which are testable through the usual practices of natural or social science. Although particular ideas may be rejected or supported, the program of research on resilience itself is evaluated in a different way. As long as resilience thinking produces interesting research ideas, people are likely to pursue it. When it seems empty of ideas, it will be abandoned or transformed into something else.

The multifarious character of resilience has led to many definitions (Walker et al. 2004) and therefore, to diverse models and empirical analyses. At the time of writing, the Resilience Alliance (http://www .resalliance.org) states that resilience has three characteristics: (1) the amount of change the system can undergo and still retain the same controls on function and structure, (2) the degree to which the system is capable of self-organization, and (3) the ability to build and increase the capacity for learning and adaptation. Most models of resilience employ the first definition. For example, resilience of lake districts can be measured by the distance from the current state to thresholds of ecological or social change (Carpenter and Brock 2004). Many other papers use distance-to-threshold to investigate social-ecological systems (e.g., Kondolf et al. 2006, Martin 2004, Peterson 2002, Sandker et al. 2007, Walker and Meyers 2004). The second and third definitions are related to the autopoietic, or selfcreating, aspects of living systems. In biological systems, these ideas are related to the notion of 
allostasis in physiology (see below) and evolvability in population genetics (Wagner 2005). Some aspects of these definitions have been explored using models of adaptive learning, control, or management (Anderies et al. 2007, Brock and Carpenter 2007, Carpenter et al. 1999, Walters 1986). Agent-based models have been used to study the emergence of alternative approaches for managing social-ecological systems (Janssen and Carpenter 1999, Schlüter and Pahl-Wostl 2007). Emergence and transformation seem related to the functioning of networks within social-ecological systems, prompting models of various kinds of networks (Janssen et al. 2006). Models of threshold effects, evolutionary game theoretic adaptive phenomena on networks, and emergence and transformation also loom large in social science poverty research (Bowles et al. 2006). In much of the research on poverty traps discussed by Bowles et al. (2006), networks are used to model "social capital" that gives a social community adaptive capacity.

Adaptive capacity, the ability of a system to adjust to changing internal demands and external circumstances, is a central feature of resilience. Unlike distance-to-threshold models, no general and minimalist framework has developed for modeling dynamics of adaptive capacity in socialecological systems. Agent models perhaps come the closest (Janssen and Carpenter 1999, Schlüter and Pahl-Wostl 2007). Such models have been insightful, although they may be too complex to serve as minimalist heuristics for some situations. It is useful to have models for adaptive capacity that can easily be applied in a wide range of contexts, to facilitate comparisons across systems. Here, we propose such a model.

A minimal model for adaptive capacity is suggested by the physiological concept of allostasis (Sterling 2004). Biologists distinguish adaptation through evolution and natural selection, including evolved physiological adaptations, from the physiological responses of organisms to changes in their environment. Yet these physiological responses resemble processes of adaptive control studied in the literature of engineering and systems science. Throughout this paper, we use adaptation in the general sense of system science and not in the specific sense of evolutionary theory.

Homeostasis and allostasis are different models of control that are used in biology. The concept of homeostasis proposes that organisms maintain stable internal conditions through systems of negative feedbacks. Allostasis, in contrast, proposes that organisms persist by varying physiological conditions and matching them appropriately to fluctuating inputs or internal demands. Underused physiological systems wither, whereas physiological systems that are chronically used outside the normal operating range become rigid and incapable of responding appropriately to changing environments. Allostatic models are successful in explaining some aspects of hypertension, some anxiety-related mental illnesses, and some aspects of aging (Singer et al. 2004, Sterling 2004). Pathologies of allostasis -withering of underused systems and lock-in by overused systems-resemble the notions of "poverty trap" and "rigidity trap" in socialecological systems (Gunderson and Holling 2002). Here, we introduce a model based on allostasis to explore the dynamics of adaptive capacity, and the loss of adaptive capacity in poverty or rigidity traps.

First we review the rigidity and poverty traps. This literature motivates the model. We then contrast the behavior of the model in three situations: a range of normal adaptation, a rigidity trap, and a poverty trap. We conclude with some speculations about the use of models to further explore and understand adaptive capacity of social-ecological systems.

\section{Rigidity Traps}

Rigidity traps occur in social-ecological systems when institutions become highly connected, selfreinforcing, and inflexible (Gunderson and Holling 2002). A purely ecological example is old-growth forest, in which nutrients are locked up in biomass of a few shade-tolerant species that can reproduce under the thick canopy. Such a forest cannot change from endogenous processes, but may be highly vulnerable to external disturbance by catastrophic windthrow or wildfire. In the social realm, control by corrupt political regimes (Holling 2001) and the Hindu caste system (Berkes and Folke 2002) have been proposed as examples of rigidity traps. Natural resource management organized around fixed economic production targets seeks to reduce variation in resource dynamics because natural variability is problematic for industries that depend on the resource. Such management systems are not necessarily in a rigidity trap. But where management by command and control severely reduces diversity, and forces of power and profit are 
mutually reinforcing, a rigidity trap exists (Gunderson and Holling 2002). Allison and Hobbs (2004) describe a rigidity trap from Western Australian agriculture "characterized by low potential for change, high connectedness, and high resilience." They succinctly describe a rigidity trap.

\section{Poverty Traps}

Poverty traps, unlike rigidity traps, are frequently described in popular writing. The most common meaning is a situation in which people are impoverished by circumstances beyond their control. Bowles et al. (2006) provide precise definitions, models, and estimation and measurement techniques used in social-scientific studies of poverty traps. We shall focus here on the notion of "poverty trap" as that word is used in the resilience literature: the poverty trap is a situation in which connectedness and resilience are low, and the potential for change is not realized (Gunderson and Holling 2002, Allison and Hobbs 2004). Ideas and raw materials may be abundant when systems are caught in poverty traps, but there is no capacity to focus resources on a promising idea and move the system forward (Westley et al. 2006). An ecological example is persistent drought due to vegetationatmosphere interactions in drylands (Narisma et al. 2007). If the vegetation becomes scattered and sparse, albedo increases, and local weather becomes warmer and drier. Local drought may persist even though the larger-scale climate is unchanged and the diversity of the vegetation is high. The drought cannot be broken by endogenous processes alone; relief requires a shift in weather at larger spatial scales.

Examples can also be found in social systems. Manic behavior of individuals is characterized by rapid generation of ideas, but little capacity to focus on a primary idea and move it forward. Highly creative teams may generate prototype after prototype, but in the absence of mechanisms to select one option and move it into production, the team will be stuck in a poverty trap (Westley et al. 2006). Social-ecological systems that exist in situations of chronic, recurring disaster (Erikson 1995) occupy poverty traps. Tainter (1988) describes poverty traps in which sources of novelty are gradually diminished, eventually impairing the capacity for adaptive response and leading to massive change of a social-ecological system to a new and degraded state.

\section{MINIMAL MODEL}

\section{Characteristics of Adaptive Systems Subject to Traps}

Our model is motivated by consideration of an adaptive system in a variable environment, where long-term success depends on maintaining the capacity to adapt through change. The model must explain normal adaptation to a wide range of fluctuating conditions, as well as the emergence of pathologies such as the poverty trap and rigidity trap. To do this, the model connects adaptive capacity to stress experienced by the system. Our use of stress reflects the origins of allostasis in physiology and connects our model with that literature (Sterling 2004). In ecosystem management, stress represents the degree to which resources are aggregated and focused to solve a collective problem. Focus of resources in any one dimension would reduce resources available for problem solving in other dimensions. Levin and Lubchenco (2008) note the distinction in engineering between stress and strain, the latter being the impact of stress on a system. Stress, as used in our paper, represents the cumulative effort expended by the system to adapt its internal conditions to external forces as well as changing internal demands.

Although adaptive capacity is impaired in both the poverty and rigidity traps, the traps have opposite characteristics in several important dimensions (Table 1). Heterogeneity of entities is high in the poverty trap, but network connections are sparse. There is little capacity to focus on an optimal solution to a current challenge, yet great scope for exploration of possible solutions. Stress is low, and there is high capacity to dissipate stress. In contrast, the rigidity trap is characterized by low heterogeneity and high connectivity of entities. There is great capacity to focus on a singular approach, and low capacity to explore alternatives. There is little capacity to dissipate stress, and stress may accumulate to high levels.

In animal physiology, the poverty trap resembles a person who is out of shape (Table 1). The muscles and skeletal system have a latent potential to develop strength for a wide range of activities, but this potential is untapped. A program of regular exercise could build strength. The rigidity trap, in contrast, resembles a person who has high blood pressure due to chronic overuse of a "fight or flight" response. A documented example is African- 
Table 1. Characteristics of the traps.

\begin{tabular}{lll}
\hline \hline Characteristic & Poverty Trap & Rigidity Trap \\
\hline Heterogeneity of entitities & High & Low \\
Network connections & Low & High \\
Capacity to focus & Low & High \\
Capacity to explore & High & Low \\
Average stress & Low & High \\
Capacity to dissipate stress & High & Low \\
Analog in animal physiology & Out of shape & Hypertense \\
Analog in simulated annealing & High temperature & Low temperature \\
Analog in spin-glass & Underconnected & Frozen by low thresholds \\
\hline
\end{tabular}

Americans subject to chronic stress from racial discrimination as well as the anticipation of racial discrimination (Sterling 2004).

These traps resemble two physical models used in different areas of science (Table 1). Simulated annealing (Kirkpatrick et al. 1983) is a computer algorithm for finding the deepest point of a complex multidimensional topography with many local valleys and peaks. The algorithm combines a capacity to move downhill in any locale with a capacity to explore by jumping long distances to discover new terrain. A parameter of the algorithm controls the balance of effort between local downhill movement and exploration for new valleys. In the normal course of solving a problem, this parameter changes gradually. In early stages, exploration of a wide range of valleys takes precedence. Later, when a valley that is likely the deepest has been found, the emphasis switches to downhill movement. This normal operation resembles the foreloop of the adaptive cycle (Holling 1986, Walker and Salt 2006). If simulated annealing was frozen in the exploration phase, it could be said to be in a poverty trap. If simulated annealing was frozen in the downhill phase before the deepest valley was located, it could be said to be in a rigidity trap.
Spin-glass models of memory (Hopfield 1982, Amit et al. 1985) perhaps come closer than simulated annealing to the biological roots of allostasis in physiology and adaptive capacity in socialecological systems. A spin-glass is a potentially magnetic material that is highly disordered, far from its "ground" or magnetized state, and capable of resting in any of many intermediate, locally stable states. Transitions of spin-glass among its many locally stable states are used as models of dynamic memory, to understand the neurobiology of problem solving. The flexibility of the spin-glass to occupy different locally stable states allows it to represent different complex patterns. This flexibility can be lost in ways that resemble poverty or rigidity traps. In a spin-glass model, pattern emerges from interactions of an enormous network of switches. A matrix of parameters represents the strengths of connections between each possible pair of switches. These connection parameters, combined with the present state of all the switches, determine the potential that acts on each switch. Another vector of parameters represents the list of thresholds at which each switch flips between "off" or "on." Problem-solving ability depends on maintaining the connections of the switches and their flexibility to flip. Now imagine a spin-glass in which the strength of interactions between each pair of switches decays 
if the switches are not "on" for a long time. If this spin-glass were understimulated, many of the network connections would decay away and the system would lose its ability to respond to later stimuli; that is, it would fall into a poverty trap. Conversely, consider a spin-glass in which the thresholds decay with intensive use, so that a switch that is chronically "on" loses the ability to turn "off." If this spin-glass were overstimulated, many of the switches would become locked on and the system would lose its capacity to respond to situations when switches needed to be "off;" that is, it would fall into a rigidity trap.

\section{Dynamics of Adaptive Capacity}

A simple model for dynamics of adaptive capacity has two components: an adaptive controller, and a dynamic system whose adaptive capacity depends on the magnitude of effort expended for adaptive control in the past (Appendix 1). We use a simple and familiar adaptive controller, a "proportionalintegrated-derivative," or PID, controller (Anderson and Moore 1971). A familiar example of PID control is the automated speed regulator, or cruise control, found in many automobiles. The cruise control responds to internal demands (target speeds set by the driver) as well as external conditions (such as climbing or descending hills). This model is related to models of adaptive control used in previous studies of social-ecological dynamics (Walters 1986, Carpenter et al. 1999, Brock and Carpenter 2007, Anderies et al. 2007).

We represent the relationship of adaptive capacity to stress with a hat-shaped function of cumulative stress (Fig. 1). The $\mathrm{x}$-axis represents cumulative stress $(\mathrm{S})$, a measure of the effort that the system has expended to adapt. The y-axis represents adaptive capacity, $A(S)$. At an intermediate range of $S$, adaptive capacity is relatively large. If $S$ is chronically low, the system is in a poverty trap. If $\mathrm{S}$ is chronically high, the system is in a rigidity trap. The spin-glass described above can represent this relationship. An understimulated spin-glass (left side of Fig. 1) represents a poverty trap. A socialecological example is a system where networks and leadership have not coalesced to drive forward solutions to problems, even though many good ideas for solving the problems may exist (Westley et al. 2006). An overstimulated spin-glass (right side of Fig. 1) represents a rigidity trap. A social-ecological example is a rigidly bureaucratic agency that is unable to assimilate new information from the system that it governs (Gunderson et al. 1995).

A simulation with $\mathrm{S}$ fluctuating in the adaptive range illustrates a system with high adaptive capacity (Fig. 2). The target (Fig. 2A, dark blue dash) and external forcing (Fig. 2B, pink) vary over time. The magnitude of adaptive control (Fig. 2B, green) changes to bring the system state (Fig. 2A, light blue) in the neighborhood of the target (Fig. 2A, dark blue dash). Cumulative stress (Fig. 2C) and adaptive capacity (Fig. 2D) fluctuate in the adaptive range.

If Fig. 2 represented a model of a person's blood pressure throughout a day, the changes in the target would represent changing demands due to, say, exercise, need to focus intensely on a difficult task, relaxation during a meal, or sleep. External forcing would represent unexpected shocks, such as a nearaccident while bicycling to work, an unexpectedly stressful meeting, or an opportunity for a nap. Normal blood pressure is not a homeostatic constant. Rather, it is the capacity to adjust blood pressure to changing demands and external events, and to maintain this capacity into the future.

If Fig. 2 represented a model of resource use by a social-ecological system, the changes in the target would represent changing demands due to human decisions, and external forcing would represent external shocks to social or ecological components of the system. Adaptive resource use is not extraction at a fixed rate. Rather, it consists of the capacity to adjust resource use appropriately to changing demands and external events, while maintaining future capacity to use the resource at appropriate levels.

\section{Rigidity Trap}

Fig. 3 portrays a system in a rigidity trap. The time series for the target and the external forcing are identical to those used in Fig. 2 to illustrate normal adaptive dynamics. The difference is that in Fig. 3 the system has been chronically overstressed so that $\mathrm{S}$ does not decay back to the adaptive range. A high magnitude of control is necessary to drive the state variable back toward the target (Fig. 3B), but changes in demand and external forcing lead to wild overshooting and undershooting of the target (Fig. $3 \mathrm{~A}$ ). Note that the magnitudes and fluctuations of the control in the rigidity trap (Fig. 3B) are large 
Fig. 1. The adaptive capacity function $A(S)$ vs. S.

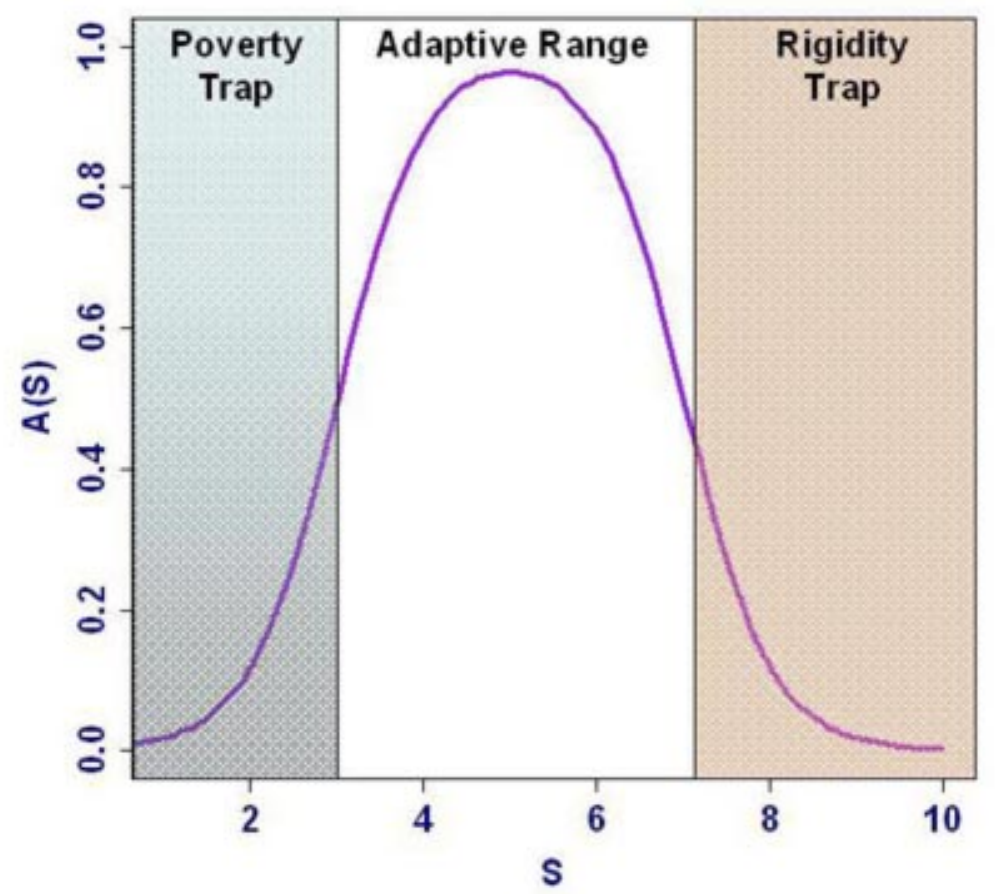

compared with those seen in the adaptive range (Fig. 2B). Stress accumulates to high levels (Fig. 3C) and adaptive capacity drops to near zero (Fig. 3D).

In human physiology, some kinds of hypertension are characterized by inability to regulate blood pressure (Sterling 2004). Blood pressure fluctuates widely with changes in physiological demands or external stresses. Although hypertension is associated with high blood pressure, deaths from hypertension are often associated with episodes of low blood pressure (Sterling 2004).

In social-ecological systems, intensive management of some dimensions of the system may allow wide excursions in other dimensions. For example, U.S. forest policy of the $20^{\text {th }}$ century emphasized commercial harvest and fire suppression. Meanwhile stand age structure shifted and fuel density increased. More people and dwellings infiltrated the forest, creating a mixed wildsuburban landscape. Non-commercial uses of the forests increased. Climate change led to drier conditions and increased risk of wildfire. Thus, the nature of the problem has changed completely, in part as a consequence of policies designed to address the problems of decades ago.

If the cumulative stress is decreased, then adaptive capacity can grow. In the blood pressure example, avoidance of anxiety-producing interactions might decrease stress. In the forest management example, allowance for diverse fire regimes might decrease stress. Dynamics during stress reduction are illustrated by linearly decreasing average accumulated stress ( $\mathrm{S}^{*}$, Appendix 1) from 9 to 5 over 1000 time steps (Fig. 4). Adaptive capacity rises (Fig. 4A) and integrated deviations from the target gradually decrease (Fig. 4B). The magnitude of control, a measure of the effort needed to adjust toward the target, declines (Fig. 4C). 
Fig. 2. Example of dynamics with stress levels in the adaptive range $\left(S^{*}=5\right)$. (A) State variable y (light blue) and target $\mathrm{y}^{*}$ (dark blue dash). Standard deviation of the distance of y from the target is 0.24. (B) Control magnitude $u$ and disturbance n. (C) Stress S. (D) Adaptive capacity A(S).

A. state variable

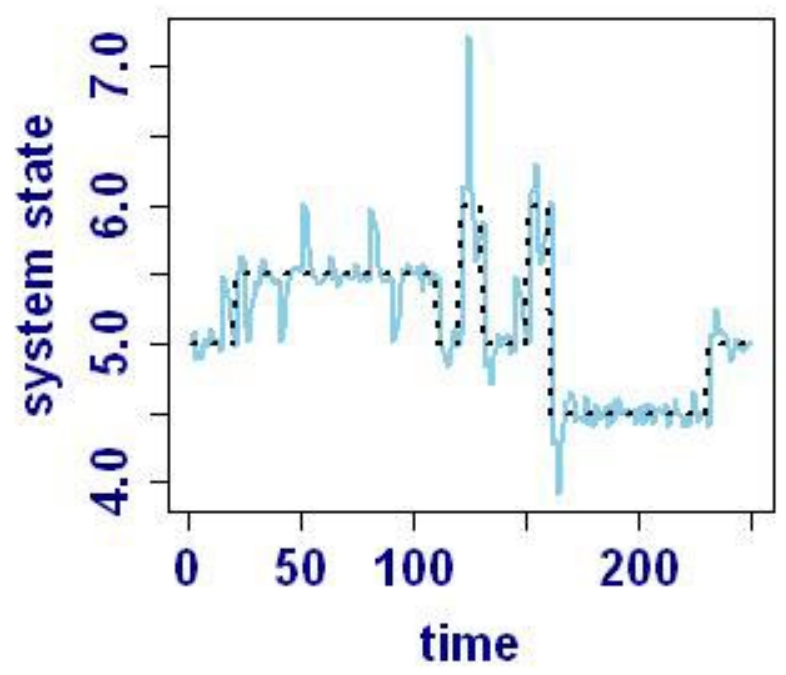

C. stress time series

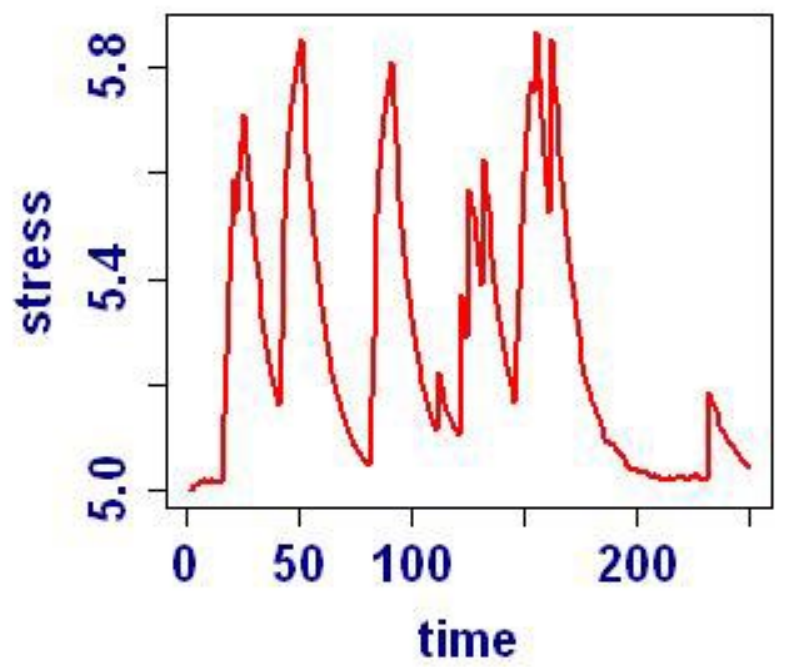

B. control (green), forcing (pink)

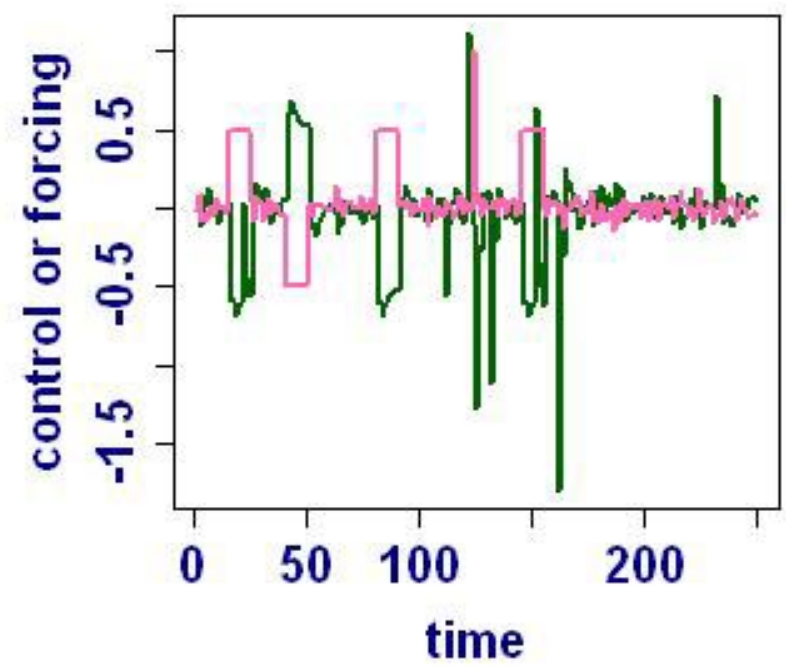

D. value of $A(S)$

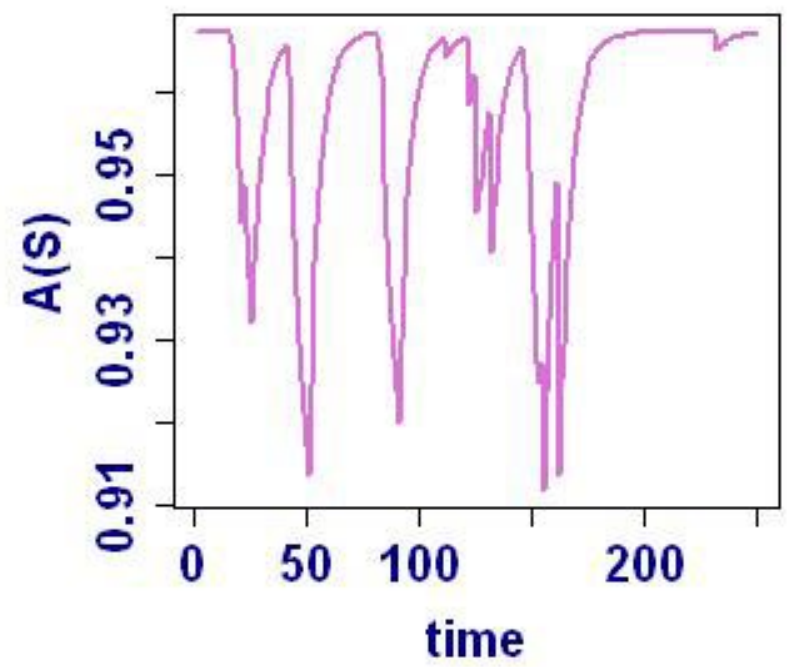


Fig. 3. Example of dynamics in the rigidity trap $\left(S^{*}=8\right)$. (A) State variable y (light blue) and target $y^{*}$ (dark blue dash). Standard deviation of the distance of y from the target is 1.41. (B) Control magnitude $u$ and disturbance n. (C) Stress S. (D) Adaptive capacity A(S).

A. state variable

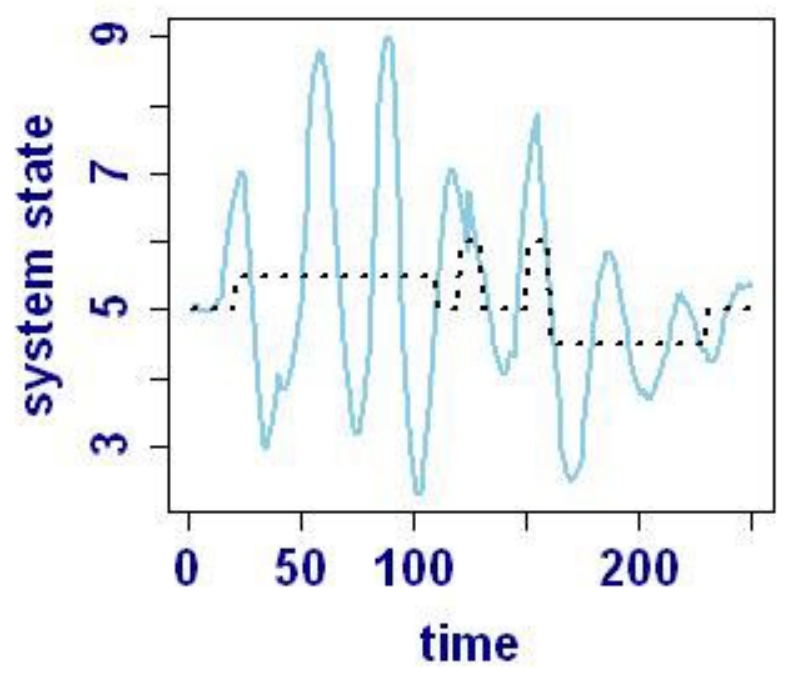

C. stress time series

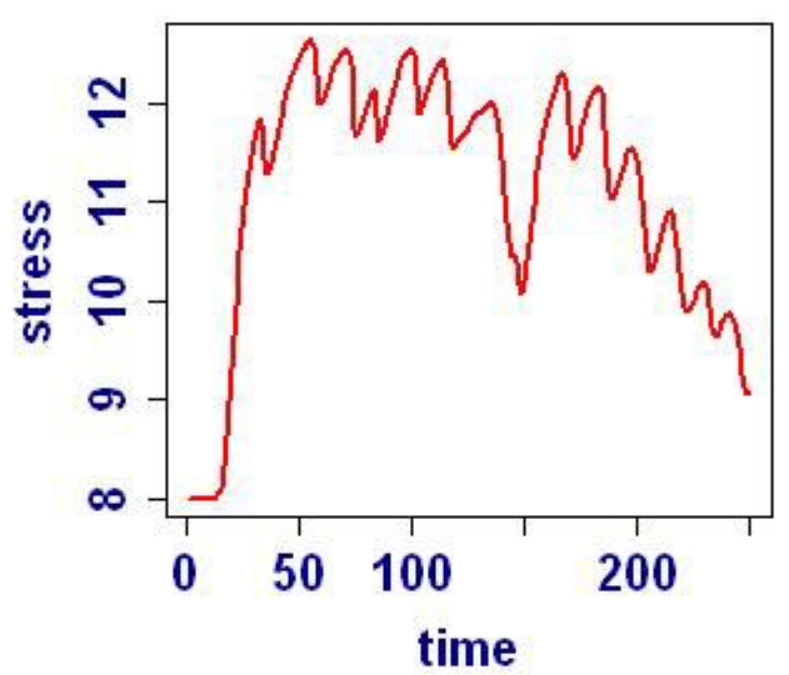

B. control (green), forcing (pink)

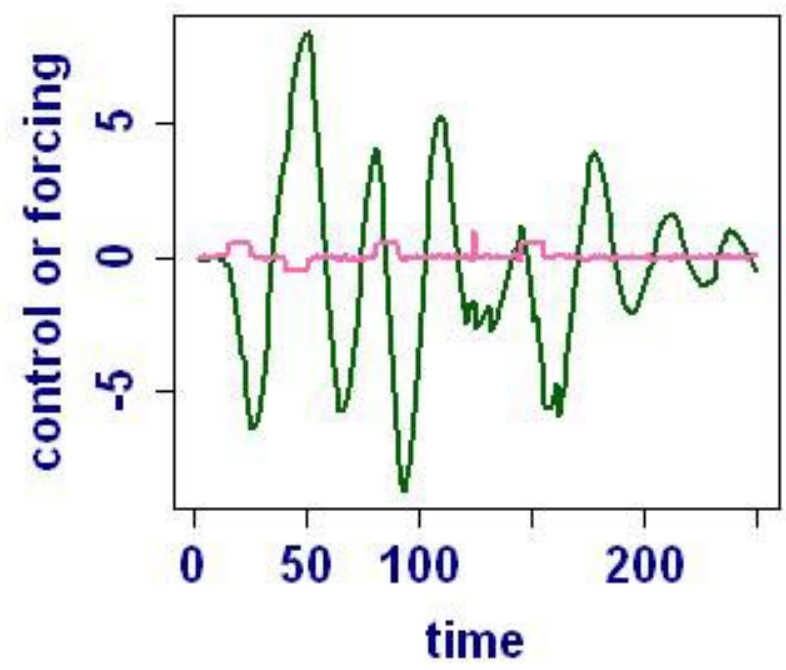

D. value of $A(S)$

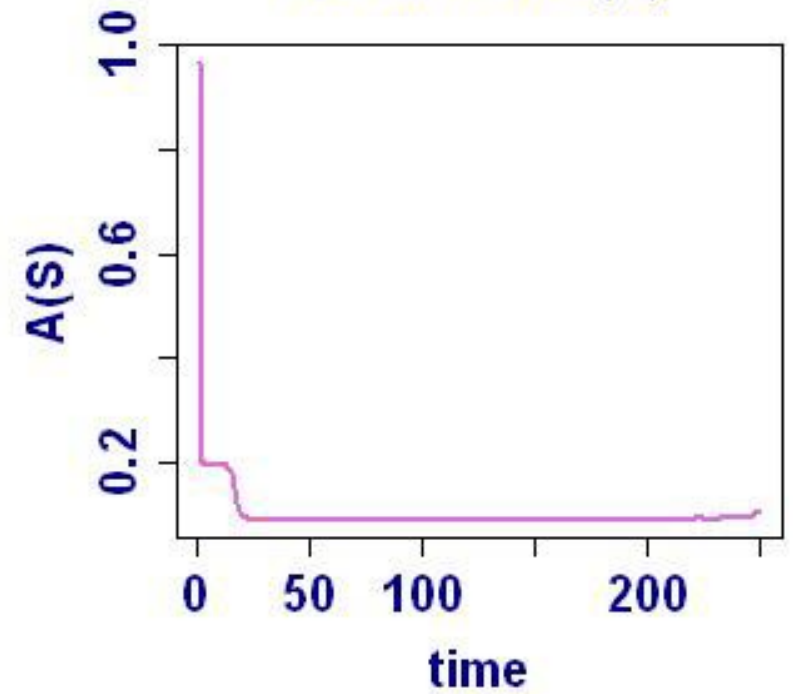


Fig. 4. Emerging from a rigidity trap: time series as $S^{*}$ is lowered gradually from 9 to 5 over 1000 time steps. (A) Adaptive capacity A(S[t]). (B) Integrated deviation from target, $\mathrm{q}[\mathrm{t}]$. (C) Squared control, $\mathrm{u}[\mathrm{t}]$ $\wedge 2$.

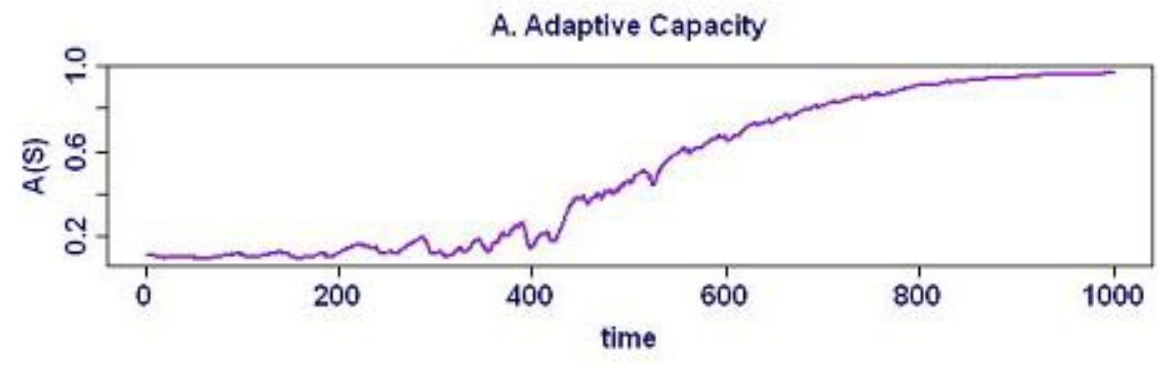

B. Integrated Deviation from Target

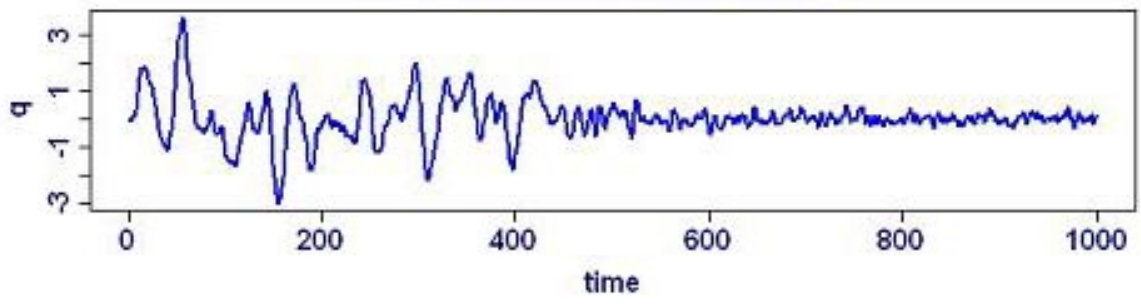

C. Squared Control

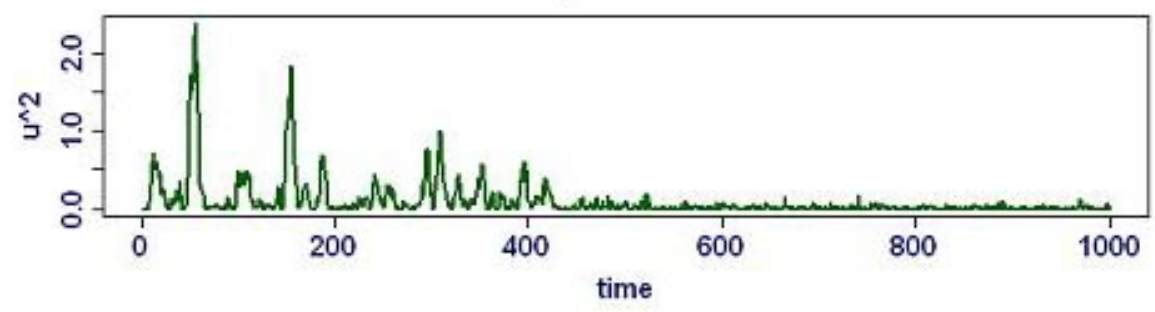

\section{Poverty Trap}

In Fig. 5, we see a potentially adaptive system that is chronically underused. The time series for the target and the external forcing are identical to the ones seen in normal adaptive dynamics (Fig. 2) and the rigidity trap case (Fig. 3). In Fig. 5, however, the stress dissipates before it reaches the adaptive range. Such dynamics are characteristic of a poverty trap. Although substantial magnitude of control is applied (Fig. 5B), the system fluctuates widely around the target (Fig. 5A). As in the rigidity trap (Fig. 3B), the magnitude and fluctuations of control used in the poverty trap (Fig. 5B) are large compared with the adaptive range (Fig. 2B). Stress occasionally reaches the adaptive range (y-axis peaks larger than 3 in Fig. 5C). Yet stress quickly dissipates and the system never spends more than a few time steps with high adaptive capacity (Fig. 5D).

In human physiology, the response to stress of an out-of-shape individual resembles Fig. 5. Even a short period of exertion, such as climbing stairs, results in wide swings in breathing, heart rate, or blood pressure. Of course a sustained program of gradually increasing exercise can move the person's physiology into the adaptive range.

In social-ecological systems, Fig. 5 resembles a situation with great turbulence of ideas, but no focus or leadership to channel the ideas toward solution 
Fig. 5. Example of dynamics in the poverty trap $\left(S^{*}=2\right)$. (A) State variable y (light blue) and target y* (dark blue dash). Standard deviation of the distance of y from the target is 0.38. (B) Control magnitude $u$ and disturbance n. (C) Stress S. (D) Adaptive capacity A(S).

A. state variable

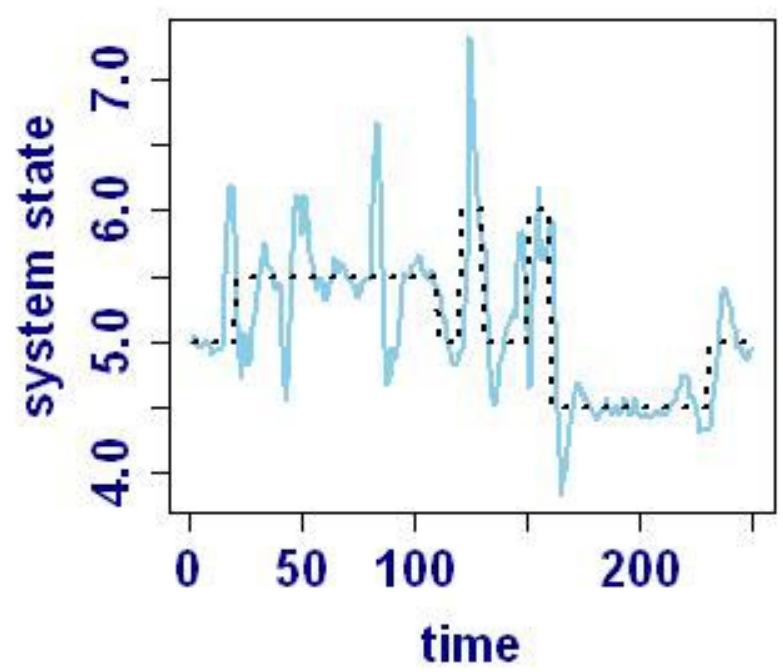

C. stress time series

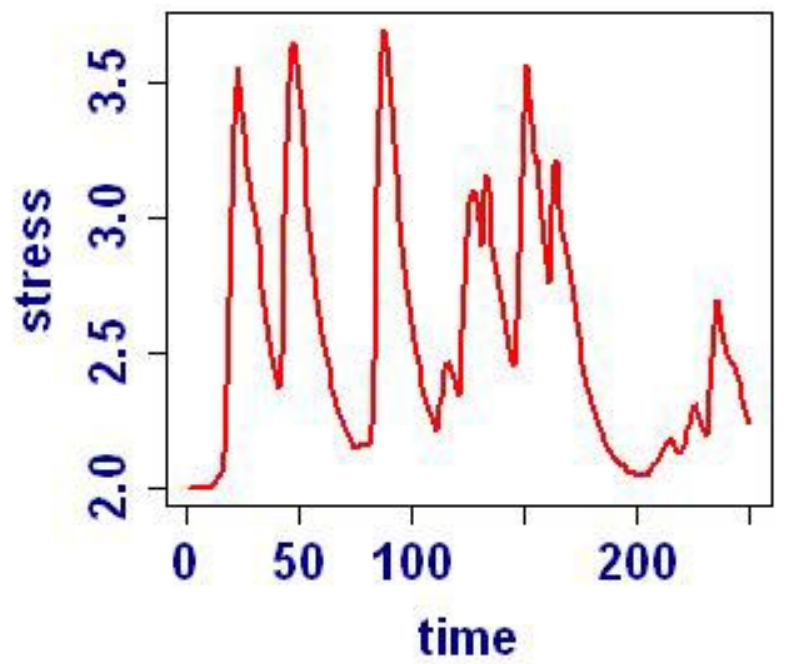

B. control (green), forcing (pink)

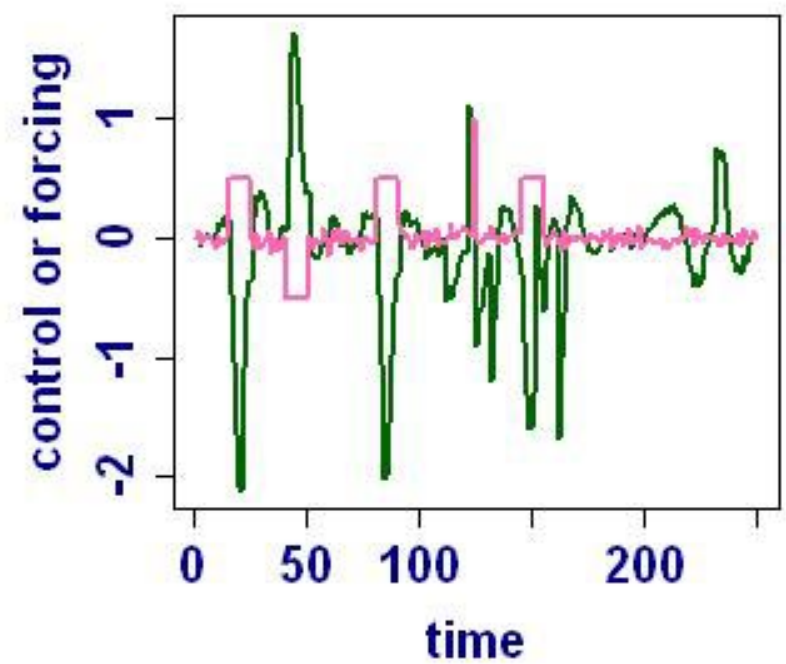

D. value of $A(S)$

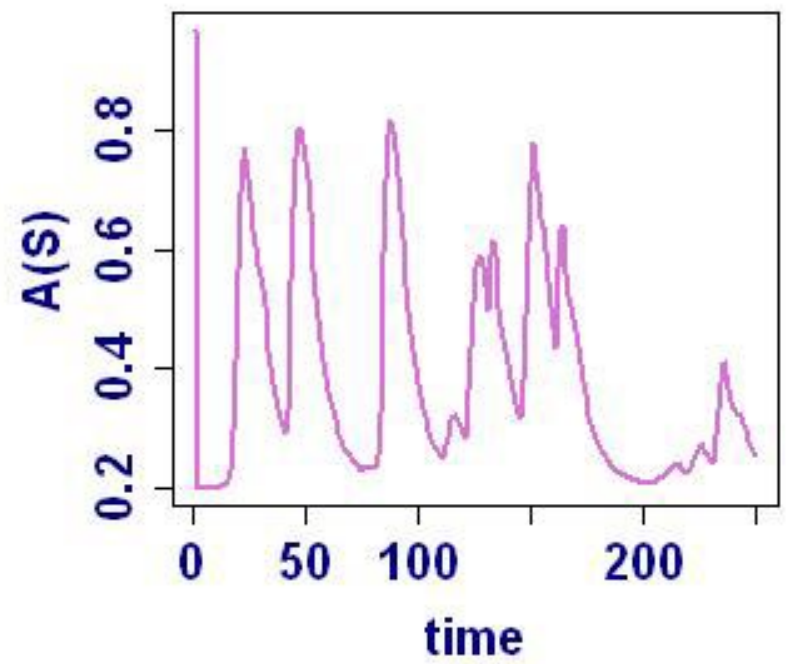


of an overarching problem. The current situation with climate change is an example. A great diversity of existing technologies could be combined to meet energy needs while decreasing use of fossil fuels (Pacala and Socolow 2004). In the near future, there are many ideas for improving energy technology, such as various forms of biofuel, solar, tidal, geothermal or fusion energy. From a different perspective, there are ideas for engineering climate, by adding soot or aerosols to the stratosphere, fertilizing the ocean, expanding land cover of grasslands and forests, or other schemes. Through the 1990s and early 2000s, climate policy seemed to be in a poverty trap, with many ideas but no agreement on the path forward. At the time of writing, it seems possible that this trap could be breaking down, as governments, corporations, and individuals become more willing to invest in actions to address climate change.

If stress accumulates, then adaptive capacity can grow out of the poverty trap. Dynamics during stress accumulation are illustrated by linearly increasing average accumulated stress ( $S^{*}$, Appendix 1) from 1 to 5 over 1000 time steps (Fig. 6). Adaptive capacity rises (Fig. 6A), integrated deviations from the target gradually decrease (Fig. 6B), and there is a decline in the magnitude of control (Fig. 6C).

\section{DISCUSSION}

Just as a whole photographic image emerges from the contrast of dark and light, understanding of social-ecological systems can emerge from the contrast of adaptive dynamics across a range of scenarios. Traps, or persistent maladaptive situations, have become an important topic for social-ecological research (Westley et al. 2006). Janssen and Scheffer (2004), for example, studied the sunk-cost effect as a mechanism of traps for ancient societies that later collapsed. Scheffer et al. (2003) modeled general patterns of trap formation in slow social responses to intensifying environmental problems. Here, we present a model that can be employed with any method of trap formation to study the contrast between adaptive and trapped dynamics, and transitions between these two contrasting dynamics. By analogy to the physiological process of allostasis, or persistence through change (Sterling 2004), the model focuses on changes in the capacity to adapt. Here, we have used the model to compare and contrast the poverty and rigidity traps.

Our analysis has emphasized the changing nature of traps. Although the word "trap" implies stasis in some dimension, a trapped system may exhibit extreme fluctuations in other dimensions. In a poverty trap, fluctuations are not harnessed for adaptation, although there are lurches toward the adaptive range. Most of these fail, and the system decays back to the region of preadaptive dynamics. Eventually, however, it is possible that the system will find its way into the adaptive range and fluctuate there for a time. In this sense, a poverty trap is unrealized potential. By contrast, in the rigidity trap, the expanding fluctuations due to overuse of control are likely to lead to a breakdown in some dimension of the system, perhaps leading to a more general collapse. Depending on the nature and magnitude of the collapse, and the post-collapse drivers and feedbacks, the system could move into the adaptive range, or a poverty trap, or disappear altogether. Understanding the pathways out of traps, and how complex systems can be guided onto one pathway or another, is an important topic for ongoing research.

The model was designed to be simple (representing adaptive capacity with relatively few equations and parameters, Appendix 1) and general (applicable to generic features of poverty and rigidity traps) for synthetic understanding of common features of broad classes of traps. It was not intended to represent the specific components or processes of any particular real-world social-ecological system. It is a quite general representation of adaptive control for a system that undergoes changes in controllability. A model for a specific socialecological system would almost certainly require a more complicated set of equations in order to represent the important details of that particular context. For example, models of regional eutrophication include equations for ecosystem dynamics, an equation for observation and synthesis, a general growth equation for performance of the regional economy, a control system to establish incentives and regulations, and hundreds of equations for behavior of individual farmers (Carpenter et al. 1999). Although these models were not constructed to study poverty or rigidity traps, behavior resembling these traps emerges from the model dynamics. 
Fig. 6. Emerging from a poverty trap: time series as $S^{*}$ is raised gradually from 1 to 5 over 1000 time steps. (A) Adaptive capacity A(S[t]). (B) Integrated deviation from target, $\mathrm{q}[\mathrm{t}]$. (C) Squared control, $\mathrm{u}[\mathrm{t}]$ $\wedge 2$.

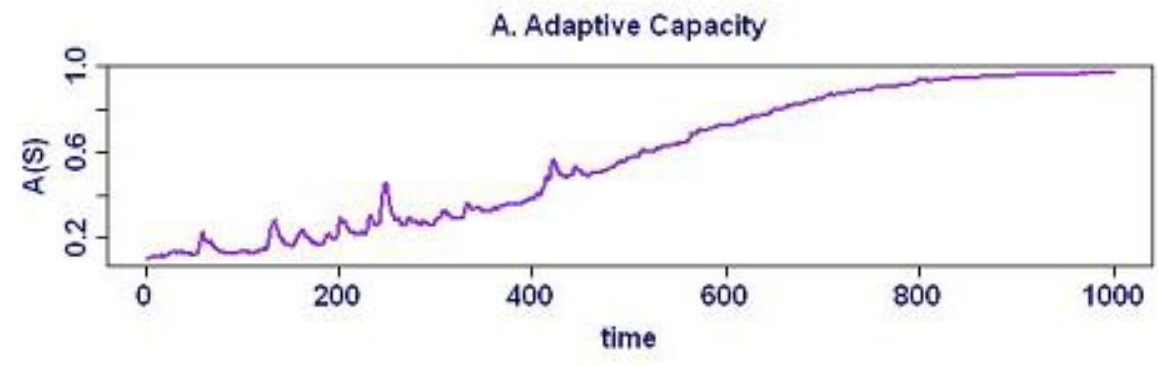

B. Integrated Deviation from Target

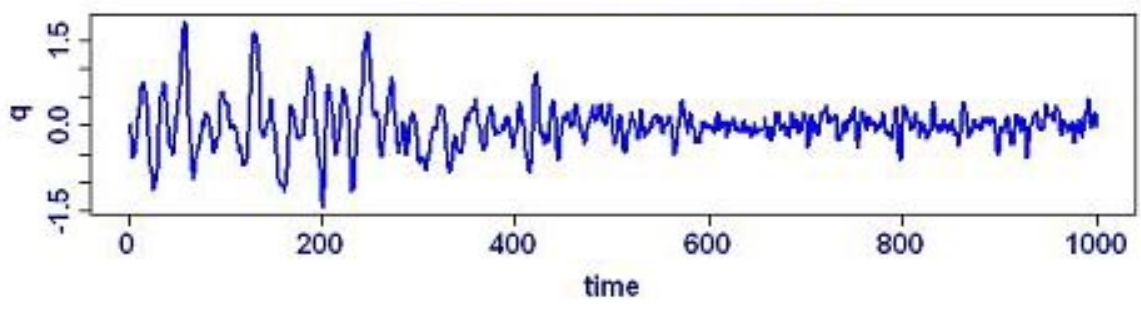

C. Squared Control

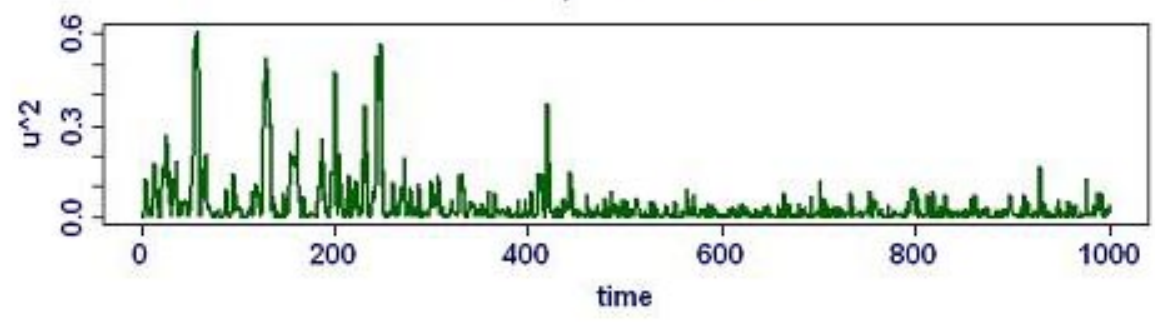

Many case studies of regional ecosystem management could be modeled within the general framework that we propose. Management of the Great Lakes of North America, for example, showed time lags of 15 to 30 years between recognition of a major problem (such as eutrophication, toxic contaminants, or sea lampreys) and development of intergovernmental institutions to address it (Francis and Regier 1995). In the early stages, there were many ideas but limited capacity to act (left side of Fig. 1). As political capacity coalesced, adaptive capacity increased and effective measures were taken to mitigate eutrophication, toxic contaminants, and sea lampreys (near the peak of Fig. 1). As these problems were brought under control, socioeconomic dependencies developed that in some cases led to rigidities (right side of Fig. 1). Contaminant control can do little about persistent contaminants that are already in the system, so agencies focused intensively on "zero discharge" leading to legal gridlock. Success in control of sea lamprey led to a sport-fishing industry worth billions of dollars per year that is completely dependent on stocking of salmonids (mostly exotic species) and the chemical control of lampreys. Thus, there is some evidence for transitions from low to high adaptive capacity, and then later decline in adaptive capacity, as governance systems address environmental problems (Gunderson et al. 1995).

Much of control theory that focuses on the general features of integral and proportional controllers (e. g., Yi et al. 2000) was not designed to display the features of traps that we explore here. We believe 
our paper is an initial attempt to combine ideas on nonlinear control problems (Isidori and Byrnes 1990, Byrnes and Isidori 2000) with a set of dynamics where controllability decays if the system is not used very much, and also decays if the system is used too much. These double threshold dynamics to govern the strength of response of the state to a unit input of control are not emphasized in the usual nonlinear control literature, much less the linear control literature. The effects of adaptive capacity resemble the effects of algorithmic complexity in modeling behavior of human agents in economics (Velupillai 2000): an agent is an effective adaptor when its algorithmic complexity is relatively high.

We believe that social-ecological research is best served by a diversity of models. Insights are likely to come from studies that carefully contrast the implications of alternative modeling approaches with field observations from particular socialecological systems. The model introduced here enriches the options for future research by focusing on adaptive capacity as a dynamic phenomenon. Changes in capacity to adapt are crucial to the outcomes. Results presented here show that the model can represent phases of the adaptive cycle of Holling (1986), as well as the poverty and rigidity traps. The approach has flexibility to represent adaptive dynamics for a wide range of state dynamics models for social-ecological systems. Thus, the model can be used as a building block of more detailed models used to study adaptive capacity in particular regions. We expect to explore these aspects in future work.

Responses to this article can be read online at:

http://www.ecologyandsociety.org/voll3/iss2/art40/responses/

\section{Acknowledgments:}

Both authors made equal contributions to this paper. W. A. B. thanks Burt Singer for stimulating him to think about allostasis. Reinette Biggs, Jereme Gaeta, Owen Langman, Matt van de Bogert, Frances Westley, two referees, and the editors provided helpful comments. We are grateful for the support of the National Science Foundation through the North Temperate Lakes Long-Term Ecological Research program.

\section{LITERATURE CITED}

Allison, H. E., and R. J. Hobbs. 2004. Resilience, adaptive capacity, and the "lock-in trap" of the Western Australian agricultural region. Ecology and Society 9(1): 3. [online] URL: http://www.eco logyandsociety.org/vol9/iss1/art3/.

Amit, D. J., H. Gutfreund, and H. Sompolinski. 1985. Spin-glass models of neural networks. Physical Review A 32:1007-1018.

Anderies, J. M., A. A. Rodriguez, M. A. Janssen, and O. Cifdaloz. 2007. Panaceas, uncertainty and the robust control framework in sustainability science. Proceedings of the National Academy of Science USA 104:15194-15199.

Anderson, B., and J. Moore. 1971. Linear optimal control. Prentice-Hall, Englewood Cliffs, New Jersey, USA.

Berkes, F., and C. Folke. 2002. The Hindu caste system and the hierarchy trap. Pages 97-98 in L. H. Gunderson and C. S. Holling, editors. Panarchy. Island Press, Washington, D.C., USA.

Bowles, S., S. Durlauf, and K. Hoff. 2006, Poverty traps. Princeton University Press, Princeton, New Jersey, USA.

Brock, W.A., and S. R. Carpenter. 2007. Panaceas and diversification of environmental policy. Proceedings of the National Academy of Sciences USA 104:15206-15211.

Byrnes, C., and A. Isidori. 2000. Output regulation in nonlinear systems: an overview. International Journal of Robotics and Nonlinear Control 10:323337.

Carpenter, S. R., and W. A. Brock. 2004. Spatial complexity, resilience and policy diversity: fishing on lake-rich landscapes. Ecology and Society 9(1): 8. [online] URL: http://www.ecologyandsociety.org/ vol9/iss1/art8/.

Carpenter, S. R., W. A. Brock, and P. C. Hanson. 1999. Ecological and social dynamics in simple models of ecosystem management. Conservation Ecology 3(2): 4. [online] URL: http://www.ecology andsociety.org/vol3/iss2/art4/. 
Erikson, K. T. 1995. A new species of trouble: the human experience of modern disasters. W. W. Norton, New York, New York, USA.

Folke, C. 2006. Resilience: the emergence of a perspective for social-ecological systems analysis. Global Environmental Change 16. doi 10.1016/j. gloenvcha.2006.02.003.

Francis, G. R., and H. A. Regier. 1995. Barriers and bridges to the restoration of the Great Lakes basin ecosystem. Pages 239-291 in L. H. Gunderson, C. S. Holling and S. S. Light, editors. Barriers and bridges to the renewal of ecosystems and institutions. Columbia University Press, New York, New York, USA.

Gunderson, L. H., and C. S. Holling, editors. 2002. Panarchy. Island Press, Washington, D.C., USA.

Gunderson, L. H., C. S. Holling, and S. S. Light, editors. 1995. Barriers and bridges to the renewal of ecosystems and institutions. Columbia University Press, New York, New York, USA.

Holling, C. S. 1973. Resilience and stability of ecological systems. Annual Review of Ecology and Systematics 4:1-23.

Holling, C. S. 1986. The resilience of terrestrial ecosystems; local surprise and global change. Pages 292-317 in W. C. Clark and R. E. Munn, editors. Sustainable development of the biosphere. Cambridge University Press, Cambridge, UK.

Holling, C. S. 2001. Understanding the complexity of economic, ecological and social systems. Ecosystems 4:390-405.

Hopfield, J. J. 1982. Neural networks and physical systems with emergent collective computational abilities. Proceedings of the National Academy of Sciences USA 79:2554-2558.

Isidori, A., and C. Byrnes. 1990. Output regulation of nonlinear systems. IEEE Transactions on Automatic Control 35:131-140.

Janssen, M. A., Ö. Bodin, J. M. Anderies, T. Elmqvist, H. Ernstson, R. R. J. McAllister, P. Olsson, and P. Ryan. 2006. A network perspective on the resilience of social-ecological systems. Ecology and Society 11(1): 15. [online] URL: http: //www.ecologyandsociety.org/vol11/iss1/art15/.
Janssen, M. A. and S. R. Carpenter. 1999. Managing the resilience of lakes: a multi-agent modeling approach. Conservation Ecology 3(2): 15 . [online] URL: http://www.ecologyandsociety.org/vol3/ iss $2 / \operatorname{art} 15 /$.

Janssen, M. A., and M. Scheffer.2004. Overexploitation of renewable resources by ancient societies and the role of sunk-cost effects. Ecology and Society 9(1): 6. [online] URL: http://www.ecol ogyandsociety.org/vol9/iss1/art6/.

Kirkpatrick, S., C. D. Gelatt, and M. P. Vecchi. 1983. Optimization by simulated annealing. Science 220:671-680.

Kondolf, G. M., A. J. Boulton, S. O'Daniel, G. C. Poole, F. J. Rahel, E. H. Stanley, E. Wohl, A. Bång, J. Carlstrom, C. Cristoni, H. Huber, S. Koljonen, P. Louhi, and K. Nakamura. 2006. Process-based ecological river restoration: visualizing threedimensional connectivity and dynamic vectors to recover lost linkages. Ecology and Society 11(2): 5. [online] URL: http://www.ecologyandsociety.org/vol11/ iss2/art5/.

Levin, S. A., and J. Lubchenco. 2008. Resilience, robustness and marine ecosystem-based management. BioScience 58:27-32.

Martin, S. 2004. The cost of restoration as a way of defining resilience: a viability approach applied to a model of lake eutrophication. Ecology and Society 9(2): 8. [online] URL: http://www.ecologya ndsociety.org/vo19/iss2/art8/.

Narisma, G. T., J. A. Foley, R. Licker, and N. Ramankutty. 2007. Abrupt changes in rainfall during the twentieth century. Geophysical Research Letters 34:L06710, doi:10.1029/2006GL028628.

Pacala, S., and R. Socolow. 2004. Stabilization wedges: solving the climate problem for the next 50 years with current technologies. Science 305:968972.

Peterson, G. D. 2002. Estimating resilience across landscapes. Conservation Ecology 6(1): 17. [online] URL: http://www.ecologyandsociety.org/vol6/iss1/ art17/.

Sandker, M., A. Suwarno, and B. M. Campbell. 2007. Will forests remain in the face of oil palm expansion? Simulating change in Malinau, 
Indonesia. Ecology and Society 12(2): 37. [online] URL: http://www.ecologyandsociety.org/vol12/iss2/ $\underline{\operatorname{art} 37 /}$.

Scheffer, M., F. Westley and W. Brock. 2003. Slow response of societies to new problems, causes and costs. Ecosystems 6:493-502.

Schlüter, M., and C. Pahl-Wostl. 2007. Mechanisms of resilience in common-pool resource management systems: an agent-based model of water use in a river basin. Ecology and Society 12 (2): 4. [online] URL: http://www.ecologyandsociety. org/vol12/iss2/art4/.

Singer, B., C. Ryff, and T. Seeman. 2004. Operationalizing allostatic load. Pages 113-149 in J. Schulkin, editor. Allostasis, homeostasis and the costs of physiological adaptation. Cambridge University Press, Cambridge, UK.

Sterling, P. 2004. Principles of allostasis: optimal design, predictive regulation, pathphysiology and rational therapeutics. Pages 17-64 in J. Schulkin, editor. Allostasis, homeostasis and the costs of physiological adaptation. Cambridge University Press, Cambridge, UK.

Tainter, J. A. 1988. The collapse of complex societies. Cambridge University Press, Cambridge, UK.

Velupillai, K. 2000. Computable economics. Oxford University Press, Oxford, UK.

Wagner, A. 2005. Robustness and evolvability in living systems. Princeton University Press, Princeton, New Jersey, USA.

Walker, B., C. S. Holling, S. R. Carpenter, and A. Kinzig. 2004. Resilience, adaptability and transformability in social systems. Ecology and Society 9(2): 5. [online] URL: http://www.ecologya ndsociety.org/vol9/iss2/art5/.

Walker, B., and J. A. Meyers. 2004. Thresholds in ecological and social-ecological systems: a developing database. Ecology and Society 9(2): 3. [online] URL: http://www.ecologyandsociety.org/vol9/ iss2/art3/.

Walker, B. H., and D. Salt. 2006. Resilience thinking. Island Press, Washington, D.C., USA.
Walters, C. J. 1986. Adaptive management of renewable resources. MacMillan, New York, New York, USA.

Westley, F., B.Zimmerman, and M. Patton. 2006. Getting to maybe. Random House of Canada, Toronton, Ontario, Canada.

Yi, T., Y. Huang, M. Simon, and J. Doyle. 2000. Robust perfect adaptation in bacterial chemotaxis through integral feedback control. Proceedings of the National Academy of Sciences 97:4649-4653. 
Appendix 1. Description of the model used in the simulations.

Please click here to download file 'appendix1.pdf'. 